\title{
Evaluation of different shallow water culture methods for the scallop Nodipecten subnodosus using biologic and economic modeling
}

\author{
Marc H. Taylor ${ }^{\text {a,* }}$, Volker Koch ${ }^{\mathrm{b}, \mathrm{c}}$, Matthias Wolff ${ }^{\mathrm{a}}$, Francisco Sínsel ${ }^{\mathrm{c}}$ \\ ${ }^{a}$ Zentrum für Marine Tropenökologie, Fahrenheitstr. 6, Bremen D-28359, Germany \\ b Departamento de Biología Marina Universidad Autónoma de Baja California Sur, La Paz, B.C.S. CP 23080, Mexico \\ c The School for Field Studies, Center for Coastal Studies, AP 15, Puerto San Carlos, B.C.S. CP 23740, Mexico
}

Received 7 January 2005; received in revised form 26 October 2005; accepted 28 October 2005

\begin{abstract}
The desire to develop sustainable small-scale aquaculture on the Baja California peninsula has focused attention toward the native scallop Nodipecten (Lyropecten) subnodosus, a species characterized by rapid growth, large size and high domestic market price. The cool upwelling waters around Bahía Magdalena seem to provide suitable conditions for $N$. subnodosus culture, yet cheaper, less technically demanding methods of culture are desired to add to the practicality of development for local resource users. Culturing in the shallow 'esteros' (reverse-estuaries) rather than in the central section of the bay may provide such an alternative. Between September 2002 and April 2003, three grow-out culture methods (suspended module, bottom and off-bottom culture) were compared at two different densities ( $40 \%$ and $60 \%$ coverage) in terms of scallop growth, mortality and associated costs, in order to create a predictive model of monetary returns. Scallops exhibited retarded growth and increased mortality during the warm, oxygen-poor water conditions of late summer (August-September), which coincided with increased reproductive activity (Gonad Index) and lowered energy reserves (Adductor Muscle Index). Growth performance was best during a period of lower temperature in late December 2002 to early January 2003. Of the six treatments, $40 \%$ density off-bottom culture provided the best grow-out conditions in terms of average growth and mortality $\left(K_{\text {year }}=0.51, Z_{\text {year }}=0.29\right)$. However, a simulation of a 10 -year culture operation accounting for the addition of a new batch of seed each year $\left(100,000\right.$ ind. year $\left.^{-1}\right)$ shows $60 \%$ density off-bottom culture $\left(K_{\text {year }}=0.44, Z_{\text {year }}=0.37\right)$ to be the most profitable (net present value $=$ US $\$ 28,631$, internal rate of return $\left.=27.0 \%\right)$. A 6 -year period is predicted before the culture is profitable. The model proved valuable in comparing profitability between culture methods and is relevant as a tool for investment decisions in other culture operations.
\end{abstract}

(c) 2005 Elsevier B.V. All rights reserved.

Keywords: Nodipecten (Lyropecten) subnodosus; Scallop; Economic modeling; Shallow culture; Muscle; Gonad; Growth; Mortality; Baja California

\section{Introduction}

The role of scallop culture along the peninsula of Baja California as a means of maintaining production and health of wild stocks has seen some success,

\footnotetext{
* Corresponding author.

E-mail address: marchtaylor@yahoo.com (M.H. Taylor).
}

particularly in Argopecten ventricosus (Chávez and Cáceres, 1992). Recently, however, scallop culture has focused more on creating sustainable options for artisanal fisheries dependant on coastal resources, many of which are considered overexploited. The desire to create small-scale aquaculture with species that have a high market value has focused attention toward the native Lion's Paw scallop Nodipecten subnodosus. 
The Lion's Paw scallop ranges in the eastern Pacific coast from Baja California to the northern coast of Peru (Keen, 1972). It is one of the largest pectinids with a maximum height around $170 \mathrm{~mm}$ yet individuals measuring $218 \mathrm{~mm}$ and a total weight of $1863 \mathrm{~g}$ have been recorded (Felix-Pico, 1991). The only commercial fishery in Mexico occurs in Laguna Ojo de Liebre in northern Baja California where conditions are favorable for growth and the shallow lagoon allows for collection by hookah diving. The species is a functioning hermaphrodite and gonad gametogenesis and maturity occurs from May to September. Individuals sampled from Laguna Ojo de Liebre spawned between September and November and larvae were found in the water column between September and December with a maximum concentration in October (Reinecke, 1996).

$N$. subnodosus maintains a high rate of growth and somatic production beyond a single growth year. In Bahía Magdalena, Racotta et al. (2003) recorded an average overall growth rate for $N$. subnodosus of 0.22 $\mathrm{mm} \cdot \mathrm{day}^{-1}$ for the 18 -month culture duration and a final adductor muscle weight averaging $55 \mathrm{~g}$. The increased size of the adductor muscle in $N$. subnodosus translates to a much higher market price than smaller species such as A. ventricosus. There exists both local and international markets for the product and fishermen can typically expect to receive around US\$12-13/kg for the adductor meat in comparison to US\$5/kg for $A$. ventricosus meats. Market prices in La Paz, B.C.S. have reached US $\$ 22 / \mathrm{kg}$ in some grocery stores for $N$. subnodosus adductor muscles (Taylor, pers. obs.).

Most studies of $N$. subnodosus to date have utilized suspended culture in modules of stacked 'Nestier' trays (Morales-Hernández and Cáceres-Martínez, 1996; Felix-Pico, 1999; Racotta et al., 2003), or in suspended pearl nets (Unzueta-Bustamante and Olivas-Valdez, 1997; Barrios et al., 2003). The trays or nets provide protection from predation and permit water circulation, while excrement material is allowed to fall outside. Higher food supply associated with the upper euphotic zone has also been shown to promote growth in some suspended culture (MacDonald and Thompson, 1986; Lodeiros et al., 1998; Lodeiros et al., 2001). These methods also have disadvantages, especially in the upper water column where fouling and more variable abiotic conditions and wave energy may lead to increased mortality. Fouling organisms (epibionts) may negatively affect growth and survival through food competition (Orensanz et al., 1991) and by reducing water flow (Duggan, 1973).

The Center for Coastal Studies, located in Puerto San Carlos in Bahía Magdalena, has performed trials of $N$. subnodosus culture at the study site in estero San Buto using suspended modules. This method proved to be cost and labor-intensive due to the high costs of culture trays and the time invested in cleaning the modules from fouling organisms. Thus, alternative methods of culture that improve grow-out conditions and are more costeffective are needed.

The main objective of the study is to evaluate the most cost effective culture method under shallow water conditions within estero San Buto, Bahía Magdalena. Specifically, we compared the grow-out of $N$. subnodosus $(>50 \mathrm{~mm})$ in shallow water conditions cultivated in three methods (suspended modules, bottom and off-bottom culture) and at two densities (40\% and 60\%). Comparisons are made in terms of growth, mortality, material costs and operational costs. Based on these results, we developed a model to simulate monetary returns in order to give recommendations for future development of Lion's Paw culture in the region.

\section{Materials and methods}

\subsection{Site description}

The study site was located in estero San Buto, a mangrove channel in Bahía Magdalena, southeast of the town of Puerto San Carlos $\left(24^{\circ} 46^{\prime} 14^{\prime \prime N}, 112^{\circ} 2^{\prime} 9^{\prime \prime} \mathrm{W}\right)$ (Fig. 1). Mangroves line most of the shore of the estero. Tides are semidiurnal with amplitude not exceeding 2.3 m. During spring low tides, extensive sand and mud flats are present in the intertidal of estero San Buto. The experiments were located about $150 \mathrm{~m}$ from shore in the subtidal zone. Water depth during spring low tides always exceeded $0.5 \mathrm{~m}$.

\subsection{Descriptions of grow-out methods}

Fig. 2 shows the experimental design for the three grow-out methods evaluated in the study. For the suspended module culture ('Modulos') method, six stacked 'Nestier' trays made up a module. The topmost tray was filled with Styrofoam to act as a float. Beneath the float, four trays were filled with the desired density of scallops. At the bottom, an empty tray was used to prevent contact with the sea floor during spring low tides. Each of the four levels was treated as a replicate and the trays were rotated after each sampling to reduce possible effects of position in the module on growth and mortality. Trays were replaced with clean ones every $3-$ 6 weeks depending on the degree of fouling. If the changing of the trays did not coincide with the regular 


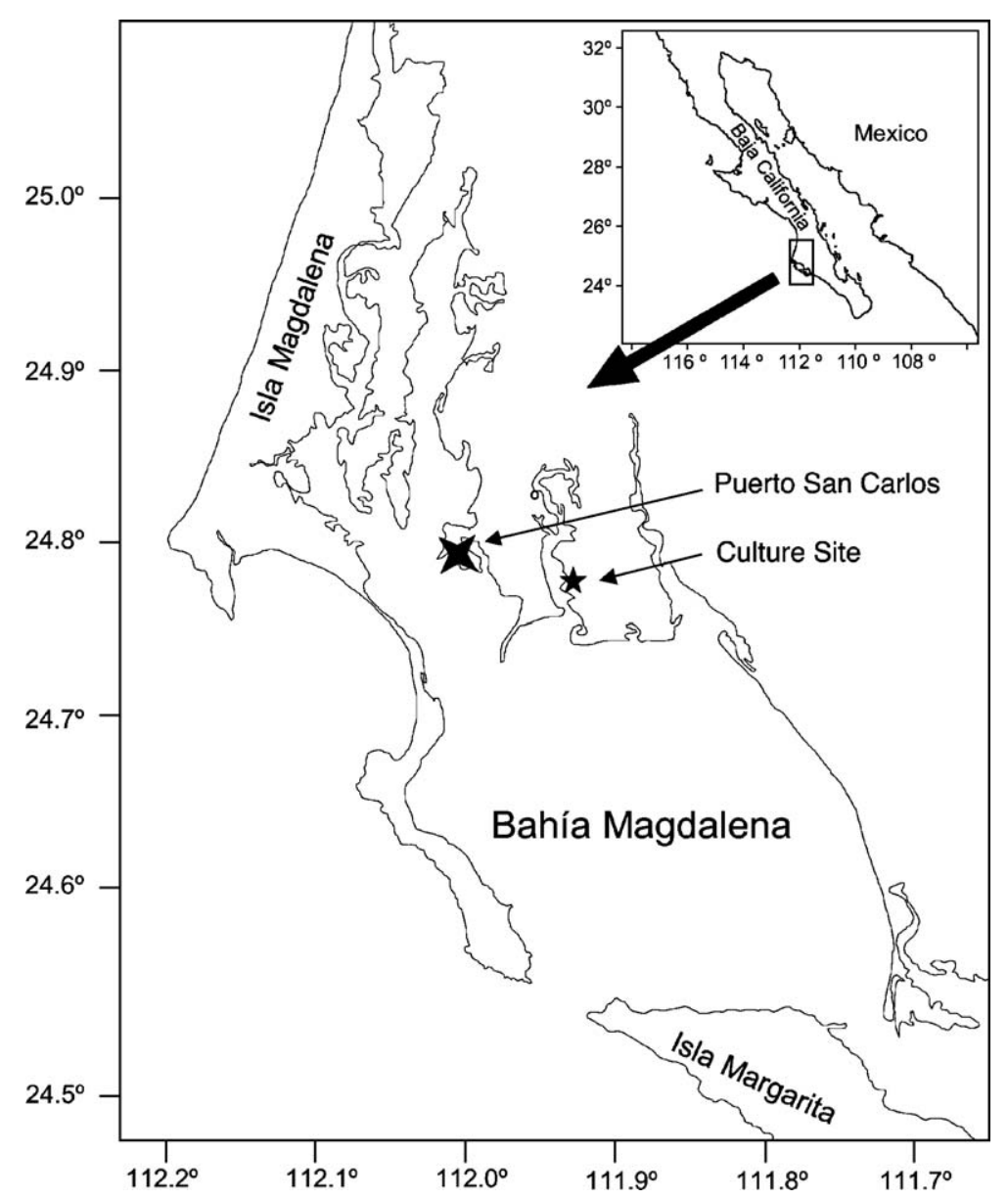

Fig. 1. Map of the Bahía Magdalena complex and study area (Koch et al., 2005).

measuring schedule only mortality would be noted and empty shells were removed.

For the bottom culture ('corrales') method, two corrals of $2 \times 4.5 \mathrm{~m}$ were constructed using $60 \mathrm{~cm}$ wide plastic-coated fencing material with a mesh size of $5 \mathrm{~cm}$. This material was tied to $1 \mathrm{~cm}$ diameter iron rebar anchored into the sediment to support the corral walls. Partitions were constructed of a similar material to divide the corrals into replicate areas of $1 \times 0.5 \mathrm{~m}$. One corral contained all $40 \%$ density replicates, while the other contained all $60 \%$ density.

For the off-bottom culture ('costales') method, $50 \times 50 \mathrm{~cm}$ plastic mesh bags were constructed of the same material as the corrals $(5 \mathrm{~cm}$ mesh size). This material was doubled and sewn with synthetic twine along its edges to create a stiff yet flexible bag that was tied to metal frame constructed of $1 \mathrm{~cm}$ diameter iron rebar. The frame was approximately $1 \times 6 \mathrm{~m}$ and was elevated $20 \mathrm{~cm}$ above the sea floor. Like cohorts and densities were tied together to form a group on the frame.
Culture density for all treatments was determined by the percent area coverage of scallops for each replicate. Replicate areas for the different methods were as follows: suspended modules $\left(3025 \mathrm{~cm}^{2}\right)$, bottom $\left(5000 \mathrm{~cm}^{2}\right)$ and off-bottom $\left(2500 \mathrm{~cm}^{2}\right)$. Average shell height (in $\mathrm{cm}$ ) of the sampled scallops was calculated and then squared, resulting in a square-form area for individual scallop. Total replicate area was then multiplied by the desired coverage (e.g. 0.4 equals $40 \%$ ) and then divided by the average individual scallop area to obtain the number of scallops needed in the replicate. Densities were readjusted once during the duration of the study for each method - off-bottom and bottom (January 20th, 2003), suspended module (February 2nd, 2003).

Two different cohorts were used to document and control for growth and mortality differences between size groups. The two cohorts were started as seed $(<5$ $\mathrm{mm}$ ) in February 2001 ('large') and October 2001 ('medium'). For each cohort, a narrow size range $(\sim 15$ 


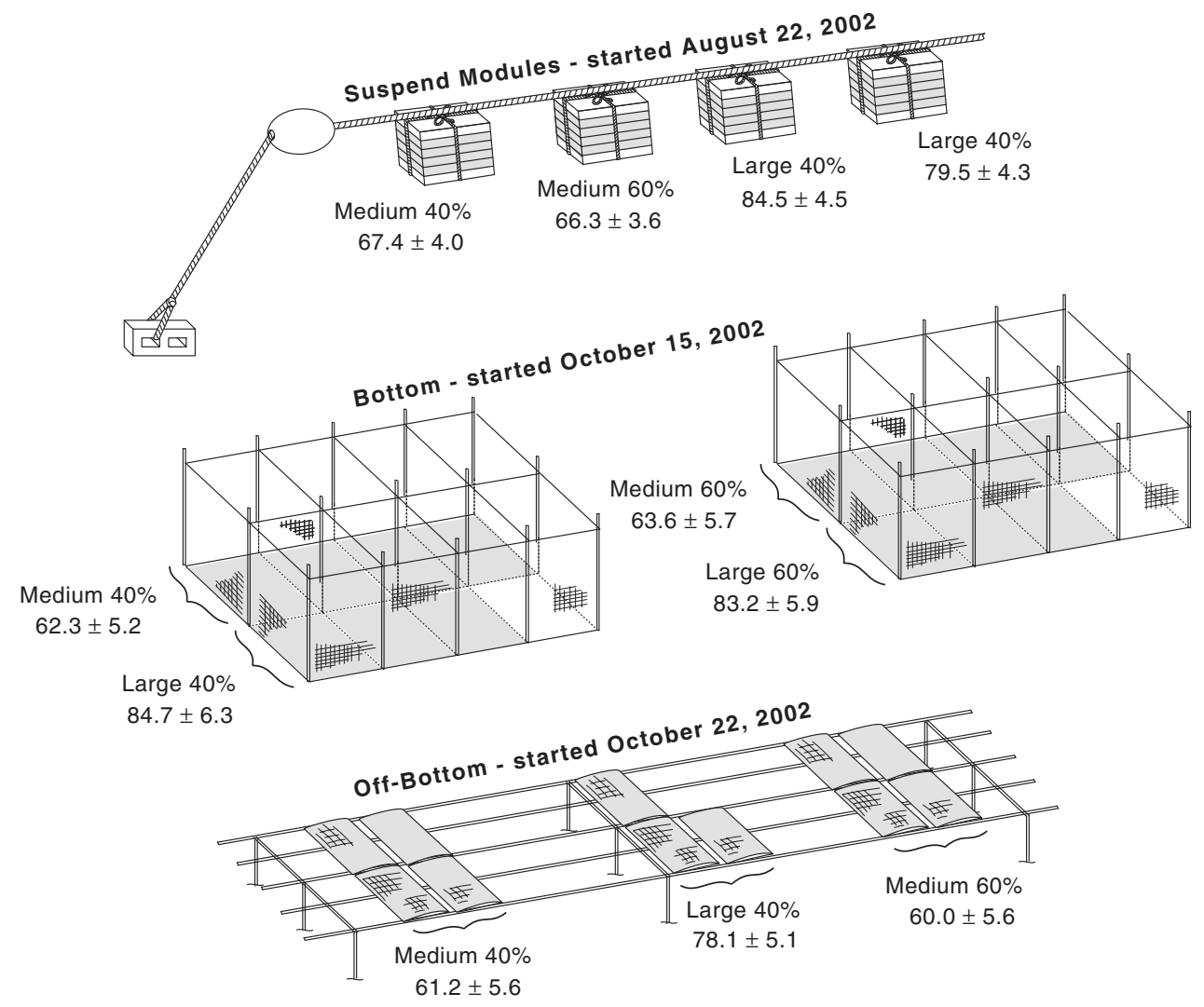

Fig. 2. Experimental design/starting culture conditions and associated mean shell height and standard deviation in millimeters. Shown are examples of how differing cohorts/densities were separated for the different methods. Shaded areas indicate replicates (not to scale).

mm of average shell height) was chosen. Each treatment contained three to four replicates. Due to a limited number of organisms, the off-bottom method did not contain a large $60 \%$ treatment (Fig. 2).

\subsection{Measuring growth and mortality}

Data on growth and mortality were collected monthly; for each treatment, the shell height of 30 scallops per replicate was measured with a caliper to the nearest $\mathrm{mm}$ (rounded down) and a monthly mean value was calculated. In cases where the number of specimen in the replicate was below 30, all organisms were measured. All dead scallops were removed and the numbers of dead and live scallops were recorded. Sampling time was minimized to prevent desiccation stress and scallops were never kept out of the water for more than $30 \mathrm{~min}$. At this time, scallop bags and corral walls were quickly cleaned of any sponges, ascidians or algae. If needed, module trays were replaced with clean ones.

Incremental growth data was fit to the special von Bertalanffy growth function (VBGF) (von Bertalanffy,
1938) using non-linear optimization methods (Generalized Reduced Gradient-GRG2) (Fylstra et al., 1998) utilized in the Microsoft ${ }^{\circledR}$ EXCEL spreadsheet by Brey (2001). The discrete form of the special VBGF was used and has the form:

$$
H_{2}=H_{1}+\left(H_{\infty}-H_{1}\right) *\left(1-\exp ^{\left(-K^{*}\left(t_{2}-t_{1}\right)\right)}\right)
$$

where $K=$ von Bertalanffy growth constant; $H_{\infty}=$ asymptotic height $(150 \mathrm{~mm}) ; H_{1}=$ average height at the beginning of the culture interval; $H_{2}=$ average height at the end of the culture interval; $\left(t_{2}-t_{1}\right)=$ time interval. Due to a lack of growth increment data from very large individuals, the fitted values for $H_{\infty}$ were underestimations given the biological knowledge of $N$. subnodosus. Therefore, $H_{\infty}$ was fixed at $150 \mathrm{~mm}$ based on the value of $170 \mathrm{~mm}$ for maximum shell height cited by Felix-Pico (1991) for Laguna Ojo de Liebre, B.C.N., yet decreased slightly to account for higher temperatures in Bahia Magdalena. The observation that warmer temperatures often lead to larger values of $K$ and smaller values of infinite shell length has been observed in other bivalve species (Vakily, 1992). The growth constant $K$ was therefore the only parameter optimized in order to minimize the sum of 
squares between the observed and calculated data. The discrete special VBGF also permitted the calculation of $K$ for each time increment, allowing for the detection of changes in growth over time.

Survival data was fit to a negative exponential mortality curve using the same non-linear optimization methods described for the growth data above. The following relationship was used (Ricker, 1975):

$N_{t_{2}}=N_{t_{1}} * \exp ^{-Z\left(t_{2}-t_{1}\right)}$

where $N_{t_{1}}=$ number of individuals at the beginning of culture interval; $N_{t_{2}}=$ number of individuals at the end of culture interval; $t_{2}-t_{1}=$ time of culture interval. Similarly, the instantaneous rate of total mortality $Z$ was optimized to minimize the sum of squares between the observed and calculated data. $Z$ was also calculated for each time increment to detect changes in mortality over time.

\subsection{Somatic production/spawning activity}

To obtain information on somatic production and spawning activity during the experimental period, once per month a random sample of adult scallops (shell height $90-110 \mathrm{~mm}, n \approx 10$ ) was removed from a separate storage corral for measurement and weighing of soft parts. Shell height, length and width were measured to the nearest millimeter, and gonad, adductor muscle and total wet weight of soft parts were weighed using a scale with accuracy to $0.01 \mathrm{~g}$. Gonad Index and Adductor Muscle Index were obtained by dividing their respective weight by the total wet weight of the soft parts and then multiplying by 100 .

An additional sample of 35 scallops over a larger size range was collected on March 2nd, 2003. This data was pooled with data from the February 18th, 2003 sample for a total of 45 individuals to obtain an adductor muscle to shell height relationship:

$\mathrm{WI}=a^{*} H^{b}$

where $\mathrm{WI}=$ individual wet weight $(\mathrm{g})$ of adductor muscle, $H=$ shell height $(\mathrm{mm})$, and $a$ and $b$ are the coefficients of the power function. This data was used in the returns model (see Section 2.7) to aid in the determination of optimal time of harvest. Continuously adjusting values for variables $a$ and $b$ that reflect the changing condition of the adductor muscle was not possible due to limitations of time and number of individuals for sacrifice. However, the period sampled probably represents a conservative estimate of the relationship considering the Adductor Muscle Index continued to increase after March for several months and the window of harvest times predicted by the returns model is around or slightly later than this date.

\subsection{Environmental parameters}

Several parameters were measured from surface waters in order to correlate growth and mortality results to environmental conditions. All parameters were sampled at the suspension line of the modules unless noted. Temperature was recorded hourly at the surface and seafloor with TidBit ${ }^{\circledR}$ Data Loggers. Oxygen was measured near the shoreline twice per week at sunrise and sunset by Winkler titration to obtain the range of concentrations before and after photosynthetic activity. Fecal coliform bacteria concentrations were determined weekly by culturing three pseudo-replicates at $35^{\circ} \mathrm{C}$ for $24 \mathrm{~h}$ with m-ColiBlue24 growth medium. Chlorophyll (Chl) $a$ was determined spectrophotometrically with the acetone extraction method (Strickland and Parsons, 1972). Turbidity was obtained with a Secchi disk. Salinity was measured weekly by refractometer and recorded in standard PSU.

\subsection{Statistical analysis}

An analysis of the residual sum of squares (ARSS) was employed to compare the fitted growth and survival equations (see Section 2.3) between methods, cohorts and densities (Ratkowsky, 1983). The $F$-statistic was calculated as described in Chen et al. (1992):

$$
F=\frac{\frac{\mathrm{RSS}_{\mathrm{p}}-\mathrm{RSS}_{\mathrm{s}}}{d f_{\mathrm{RSS}_{\mathrm{p}}}-d f_{\mathrm{RSS}_{\mathrm{s}}}}}{\frac{\mathrm{RSS}_{\mathrm{s}}}{d f_{\mathrm{RSS}_{\mathrm{s}}}}}
$$

where $\mathrm{RSS}_{\mathrm{p}}=\mathrm{RSS}$ of each function fitted by pooled data, $\mathrm{RSS}_{\mathrm{s}}=$ sum of the RSS of each individual sample and $d f=$ associated degrees of freedom (equals total sample size $(N)$ minus 1 ; one variable being estimated, $K$ or $Z$ ).

Index values were transformed to arcsine values and analyzed using one-way ANOVA and Tukey's HSD test for post-hoc comparison (Sokal and Rohlf, 1995).

\subsection{Construction of returns model}

\subsubsection{Modeling growth and mortality}

Using the data obtained on growth, mortality and estimated costs of materials and labor, it was possible to construct a grow-out comparison model to assess the 
economic feasibility of each culture method at an initial culture size of 100,000 seed. All six treatments were modeled ( 3 methods $\times 2$ densities). Before grow-out conditions were simulated, seed growth was described linearly using a growth rate of $0.35 \mathrm{~mm} \cdot \mathrm{day}^{-1}$ as was reported by Koch et al. (2005) for seed cultured under fall conditions (start date=October 8th) at a seed density of $1000 /$ tray in suspended modules. The following linear function was used to describe seed growth $(3-40 \mathrm{~mm})$ :

$H_{t}=H_{t_{i}}+\left(0.35\left(t-t_{i}\right)\right)$

where $H_{t}=$ height at time $(t)$ and $H_{t_{i}}=$ shell height at initial time $\left(t_{i}\right)$ (shell height of $3 \mathrm{~mm}$ ). A mortality constant $\left(Z_{\text {year }}\right)$ of 0.1744 (adapted from Koch et al., 2005) was applied to Eq. (2) for seed survival.

Upon reaching a shell height of $40 \mathrm{~mm}$, grow-out conditions were simulated using best-fit values of $K$ and $Z$ obtained through the non-linear optimization methods described in Section 2.3. An average value of medium and large cohorts was used as an input value for equations of growth and mortality in each treatment (Eqs. (1) and (2)).

\subsubsection{Calculation of costs}

All monetary values used in the economic models are as of July 2003 and are given in U.S. dollars. Costs of culture have three components: (1) operational costs or the money spent on labor, (2) materials costs and (3) initial costs to buy the scallop seed. Calculation of total culture area allows for the determination of associated materials and operational costs for each method. Total culture area is calculated with the following equation:

$\mathrm{TA}_{t}\left(\left(H_{t} / 1000\right)^{2} * N_{t}\right) / D$

where $\mathrm{TA}_{t}=$ total area $\left(\mathrm{m}^{2}\right)$ at time $(t), H_{t}=$ shell height $(\mathrm{mm})$ at time $(t), N_{t}=$ number of individuals at time $(t)$ and $D=$ density or coverage (e.g. $40 \%$ equals 0.4 ). Operational costs are cumulative and are calculated each day based on the number of people needed to clean and maintain the culture method given total culture area at time $(t)\left(\mathrm{TA}_{t}\right)$. In the case of bottom culture, it was assumed that only one worker is needed; thus, daily operational costs $\left(\mathrm{CO}_{t}\right)$ was held constant at US\$4.65 (Mexican minimum wage). For suspended module and off-bottom methods, the following equation was used:

$\mathrm{CO}_{t}=\mathrm{TA}_{t} / \mathrm{UA} / \mathrm{CE} / 160 * 4.65$

where $\mathrm{CO}_{t}=$ daily operational cost in US\$ day ${ }^{-1}$. worker ${ }^{-1}$ at time $(t) ; \mathrm{TA}_{t}=$ total culture area at time $(t)$; $\mathrm{UA}=$ culture unit area of a single suspended module 'modulo' or off-bottom 'costale' $\left(1.21 \mathrm{~m}^{2}\right.$ and $0.50 \mathrm{~m}^{2}$, respectively); $\mathrm{CE}=$ cleaning efficiency (\# of modules, costales cleaned per hour; 2 and 10 , respectively). $160=$ work hours per person per month. $4.65=$ minimum daily wage (US\$). This equation calculates the number of workers needed to clean each unit at a rate of once per month. Fractions of workers are possible (e.g. 1.53 workers), yet a default value of one (1.00) worker is returned in the case of a fraction of worker (e.g. 0.84 workers).

Cost of materials is based on two components. Materials needed to maintain scallops at the desired density both for pre-grow-out in modules ( $40 \%$ density) and for grow-out. The following equations were used: for suspended modules/off-bottom culture:

$\mathrm{CMAT}_{t}=\left(\mathrm{TA}_{t} / \mathrm{UA}\right) * C_{\mathrm{unit}}$

for bottom culture:

$\mathrm{CMAT}_{t}=\left(\left(\mathrm{TA}_{t} / \pi\right)^{0.5 * 2 \pi}\right) * C_{\text {unit }}$

where $\mathrm{CMAT}_{t}=$ cost of materials at time $(\mathrm{t}) ; \mathrm{TA}_{t}=$ total culture area at time $(t)$ (Eq. (6)); $\mathrm{UA}=$ area of single suspended module or off-bottom costale $\left(1.21 \mathrm{~m}^{2}\right.$ and $0.50 \mathrm{~m}^{2}$, respectively); $C_{\text {unit }}=$ cost of materials per suspended module or off-bottom costale (US\$14.21 and $5.58 / \mathrm{m}^{2}$, respectively) or for the circumference of a single circular bottom culture corral (most economical shape) (US\$1.92/m).

\subsubsection{Harvest value and monetary returns}

With an estimate of shell height at time (t) (Eqs. (1) and (5)), the adductor muscle weight at time $(t)$ can be calculated from the adductor muscle to shell height relationship (Eq. (3)) and is multiplied by the surviving number of individuals at time $(t)$ (Eq. (2)) to give the total harvest weight. The total harvest value is then calculated given the market price for the adductor muscle. The following formula was used:

$\mathrm{HV}_{t}=\mathrm{WI}_{t} * N_{t} * P_{\mathrm{WI}}$

where $\mathrm{HV}_{t}=$ value of harvest at time $(t)$; $\mathrm{WI}_{t}=$ weight of adductor muscle at time ( $t$ ) (Eq. (3)); $N_{t}=$ surviving number of individuals at time $(t)$ (Eq. (2)); $P_{\mathrm{WI}}=$ price per weight of adductor muscle. From empirical data, price of $N$. subnodosus meats was found to increase with the size of the adductor muscle. The model thus contains three prices based on the weight of adductor (if $\mathrm{WI}_{t}<5 \mathrm{~g}$, then $P_{\mathrm{WI}}=\mathrm{US} \$ 4.65 / \mathrm{kg}$; if $\mathrm{WI}_{t}<25 \mathrm{~g}$, then $P_{\mathrm{WI}}=\mathrm{US} \$ 7.44 / \mathrm{kg}$; if $\mathrm{WI}_{t}>25 \mathrm{~g}$, then $P_{\mathrm{WI}}=\mathrm{US}$ $\$ 12.09 / \mathrm{kg})$. 
Returns are calculated by subtracting the cumulative costs from the value of harvest. The following equation was used:

$R_{t}=\mathrm{HV}_{t}-\left(\mathrm{CSEED}+\mathrm{CMAT}_{t}+\sum_{t=0}^{t} \mathrm{CO}_{t}\right)$

where $R_{t}=$ returns at time $(t) ; \mathrm{HV}_{t}=$ harvest value at time $(t)$ (Eq. 10); CSEED $=$ cost of seed (US\$1395 per 100,000 seed; Mazón-Suastegui, pers. comm.); $\mathrm{CMAT}_{t}=$ cost of materials at time $(t)$ (Eqs. (8) and (9)); $\sum_{t=0}^{t}=$ accumulated operational costs at time $(t)$.

A 10-year culture operation was simulated for the best performing treatment (off-bottom $40 \%$ and $60 \%$ density) using standard financial evaluation methods of net present value (NPV) and internal rate of return (IRR) (Solomon and Pringle, 1977). The NPV discount rate is provided by the Banco de México and is calculated as bank prime rate $+2 \%(6.6 \%)$ (CETES-Federal Treasury Certificates at 28 days). A new cohort of seed is started every year and a yearly depreciation value given the 'lifespan' of the materials of grow-out materials is applied after the first harvest (10 years for seed grow-out
- suspended modules; 5 years for grow-out-offbottom 'costales'). NPV is calculated as:

$\mathrm{NPV}_{t}=\sum_{t=1}^{t} \frac{C_{t}}{(1+r)^{t}}-C_{0}$

where $C_{t}=$ the net flows during the timestep $(t)$ (calculated daily), $r=$ discount rate and $C_{0}=$ initial costs. The IRR is calculated as the rate $(r)$ that returns a value of zero (0) for NPV. NPV and IRR were then calculated for culture operations of varying size to view changes in profitability. A sensitivity analysis of some of the model's input parameters was also performed through adjustments of single input parameters by $\pm 10 \%$ and recording the resulting change in NPV for a 10 -year culture operation.

\section{Results}

\subsection{Growth}

All treatments showed a similar pattern of growth where $K$ was elevated around the month of January (Fig. 3 ). Off-bottom culture had the highest recorded $K$ values
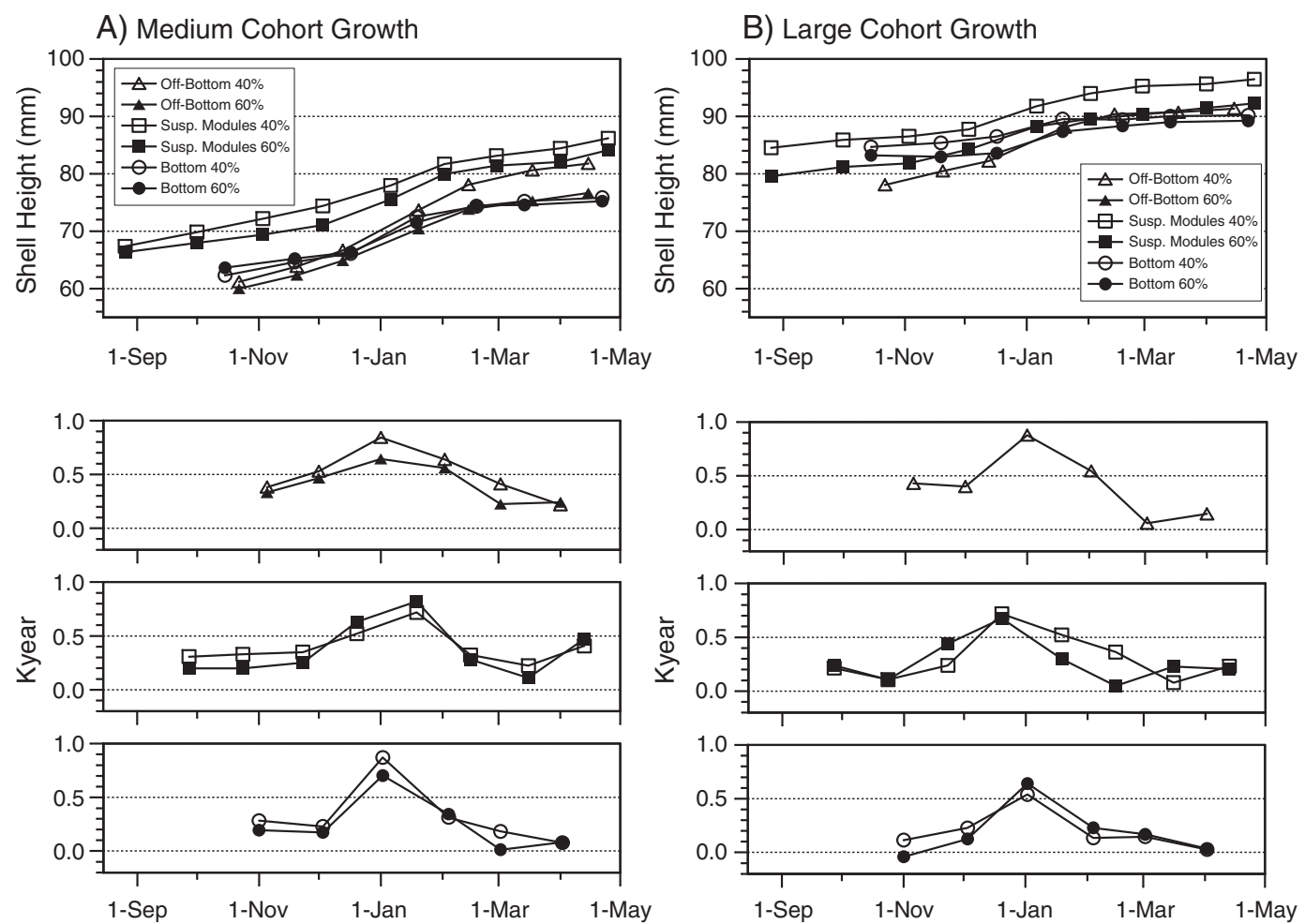

Fig. 3. N. subnodosus growth and corresponding von Bertalanffy growth constant $\left(K_{\text {year }}\right)$. Treatments are grouped by medium (A) and large (B) size

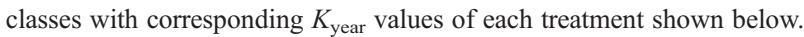


Table 1

Von Bertalanffy growth constant $\left(K_{\text {year }}\right)$ and corresponding $r^{2}$ for each treatment

\begin{tabular}{|c|c|c|c|c|c|c|c|c|}
\hline \multirow[t]{2}{*}{ Method } & \multicolumn{2}{|c|}{ Medium $40 \%$} & \multicolumn{2}{|c|}{ Medium $60 \%$} & \multicolumn{2}{|c|}{ Large $40 \%$} & \multicolumn{2}{|c|}{ Large $60 \%$} \\
\hline & $K_{\text {year }}$ & $r^{2}$ & $K_{\text {year }}$ & $r^{2}$ & $K_{\text {year }}$ & $r^{2}$ & $K_{\text {year }}$ & $r^{2}$ \\
\hline Bottom & 0.3303 & 0.82 & 0.2658 & 0.81 & 0.1943 & 0.76 & 0.1854 & 0.66 \\
\hline Off-bottom & 0.5451 & 0.95 & 0.4362 & 0.95 & 0.4711 & 0.87 & & \\
\hline Suspended module & 0.3854 & 0.95 & 0.3461 & 0.93 & 0.3083 & 0.90 & 0.3006 & 0.91 \\
\hline
\end{tabular}

Calculated through best-fit iteration of growth increment data to the specialized VBGF using non-linear optimization methods.

overall (Table 1) and ARSS revealed significantly different fitted growth curves between off-bottom and suspended modules at $40 \%$ culture density $(P<0.01)$ and between off-bottom and bottom culture at $40 \%$ $(P<0.001)$ and $60 \%(P=0.02)$ culture densities (Table $3)$. Suspended modules and bottom culture did not have significantly different growth curves at either density. Comparisons between cohorts (medium vs. large) and culture densities $(40 \%$ vs. $60 \%)$ also did not show significant differences.

\subsection{Mortality}

Survivorship was highly variable between culture methods. Suspended module and bottom culture showed higher values for $Z$ at the beginning of the study period

\section{A) Medium Cohort Growth}
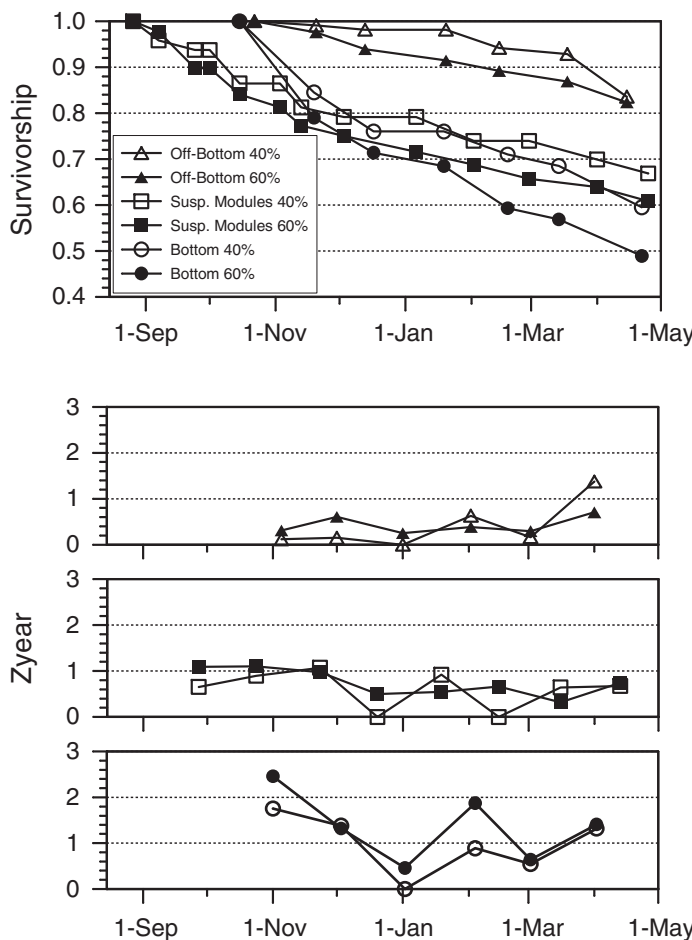

yet no other clear temporal trends were observed (Fig. 4). Bottom culture had the highest overall $Z$ values for all treatments (Table 2). ARSS revealed significant differences among fitted survivorship curves between methods at both densities. Differences were highest when comparing bottom culture survival to the other two methods (all $P<0.001$ ) (Table 3). Survivorship did not differ significantly between cohorts (medium vs. large) in all but one treatment-bottom $60 \%(P=0.02)$. Culture density $(40 \%$ vs. $60 \%)$ also did not show significant differences.

\subsection{Somatic production/spawning activity}

Gonad indices continue to decrease until December 14th, 2002 (mean Gonad Index $=5.75 \pm 1.90 \%$ ) after

\section{B) Large Cohort Growth}
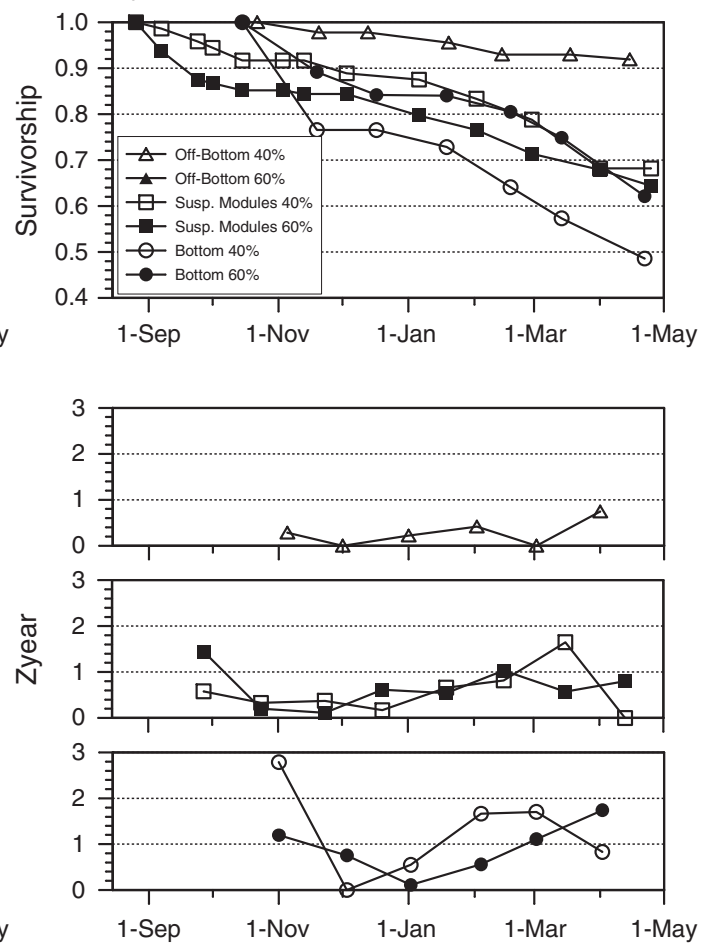

Fig. 4. N. subnodosus survival and instantaneous rate of total mortality $\left(Z_{\text {year }}\right)$. Treatments are grouped by medium (A) and large (B) size classes with corresponding $Z_{\text {year }}$ values of each treatment shown below. 
Table 2

Instantaneous rate of total mortality $\left(Z_{\text {year }}\right)$ and corresponding $r^{2}$ for each treatment

\begin{tabular}{|c|c|c|c|c|c|c|c|c|}
\hline \multirow[t]{2}{*}{ Method } & \multicolumn{2}{|c|}{ Medium $40 \%$} & \multicolumn{2}{|c|}{ Medium $60 \%$} & \multicolumn{2}{|c|}{ Large $40 \%$} & \multicolumn{2}{|c|}{ Large $60 \%$} \\
\hline & $Z_{\text {year }}$ & $r^{2}$ & $Z_{\text {year }}$ & $r^{2}$ & $Z_{\text {year }}$ & $r^{2}$ & $Z_{\text {year }}$ & $r^{2}$ \\
\hline Bottom & 1.0514 & 0.83 & 1.6331 & 0.63 & 1.5627 & 0.69 & 0.9113 & 0.80 \\
\hline Off-bottom & 0.3205 & 0.61 & 0.3706 & 0.84 & 0.2577 & 0.75 & & \\
\hline Suspended module & 0.5347 & 0.85 & 0.7533 & 0.88 & 0.5922 & 0.85 & 0.6599 & 0.93 \\
\hline
\end{tabular}

Calculated through best-fit iteration of survival data to a mortality curve using non-linear optimization methods.

which there were no significant changes or recovery of gonad weight by the last sampling on April 15th, 2003 (Fig. 5). All values after December 14th (39.56$44.53 \%$ ) were significantly higher than those values before $(33.20-35.16 \%)$.

Adductor muscle indices continue to show monthly increases from the lowest value recorded on November 25th, 2002 (mean Adductor Muscle Index $=33.21 \pm$ $4.85 \%$ ) to the highest value recorded on the last sampling, April 15th, 2003 (mean Adductor Muscle Index $=44.53 \pm 5.06 \%$ ) (Fig. 5).

A high goodness of fit value was obtained for the shell height/adductor muscle relationship, where $a=1.26 \times 10^{-5}$ and $b=3.144\left(r^{2}=0.962\right)$.

\subsection{Abiotic conditions}

Fig. 6 shows the abiotic parameters recorded during the study period. Water temperature varied little between the surface and bottom of the water column and thus only temperatures recorded at the bottom are presented. Values ranged from $17.0{ }^{\circ} \mathrm{C}$ to $31.4{ }^{\circ} \mathrm{C}$ on December 27th, 2002 and September 18th, 2002, respectively. Oxygen ranged from 2.5 to $9.4 \mathrm{mg} \cdot \mathrm{l}^{-1}$ on August 15th, 2002 and March 19th, 2003, respectively. Generally, oxygen levels were lower in the mornings than the afternoons and were negatively correlated to temperature. Secchi depth was inversely correlated with temperature. Values ranged between 2.0 and $5.3 \mathrm{~m}$. Clearest water conditions were recorded on December 27th, 2002. Chl $a$ ranged from 2.0 to $5.0 \mathrm{mg} \cdot \mathrm{m}^{-3}$. The highest value was recorded at the beginning of the study on September 23rd, 2002. No visible correlation of Chl $a$ to other abiotic parameters is evident. Fecal coliform concentrations remained low throughout the study period with two higher counts of 18.3 and 16.7 colonies $100 \mathrm{ml}^{-1}$ obtained on December 14th, 2002 and April 11th, 2003, respectively. All other values were below 7 colonies $\cdot 100 \mathrm{ml}^{-1}$. Salinity values were only available for the months of December and January, and

Table 3

Statistical comparisons of the effect of culture cohort, density and method on growth and survival by analysis of residual sum of squares (ARSS)

\begin{tabular}{|c|c|c|c|c|c|c|c|c|c|c|c|c|c|}
\hline \multirow[t]{2}{*}{ Test } & \multirow[t]{2}{*}{ Comparison between } & \multicolumn{6}{|c|}{$\begin{array}{l}\text { VBGF: } H_{2}=H_{1}+\left(H_{\infty}-H_{1}\right)^{*} \\
\left(1-\exp ^{\left(-K^{*}\left(t_{2}-t_{1}\right)\right)}\right)\end{array}$} & \multicolumn{6}{|c|}{ Survivorship: $N_{t_{2}}=N_{t_{1}} * \exp ^{-Z\left(t_{2}-t_{1}\right)}$} \\
\hline & & $\mathrm{RSS}_{\mathrm{p}}$ & $d f$ & $\mathrm{RSS}_{\mathrm{s}}$ & $d f$ & $\mathrm{~F}$ & $P$ & $\mathrm{RSS}_{\mathrm{p}}$ & $d f$ & $\mathrm{RSS}_{\mathrm{s}}$ & $d f$ & F & $P$ \\
\hline \multirow{3}{*}{$\begin{array}{l}\text { Cohort effect } \\
\text { (40\% density) }\end{array}$} & Off-bottom (medium vs. large) & 100.92 & 41 & 99.25 & 40 & 0.67 & 0.42 & 0.0610 & 48 & 0.068 & 47 & 0.18 & 0.67 \\
\hline & $\begin{array}{l}\text { Suspended module } \\
\text { (medium vs. large) }\end{array}$ & 114.44 & 63 & 111.66 & 62 & 1.54 & 0.22 & 0.1737 & 103 & 0.1735 & 102 & 0.10 & 0.75 \\
\hline & Bottom (medium vs. large) & 123.69 & 41 & 117.26 & 40 & 2.19 & 0.15 & 0.1965 & 48 & 0.1866 & 47 & 2.48 & 0.12 \\
\hline \multirow[t]{2}{*}{$\begin{array}{l}\text { Cohort effect } \\
\qquad(60 \% \text { density })\end{array}$} & $\begin{array}{l}\text { Suspended module } \\
\text { (medium vs. large) }\end{array}$ & 129.83 & 63 & 128.75 & 62 & 0.52 & 0.47 & 0.1355 & 103 & 0.1351 & 102 & 0.31 & 0.58 \\
\hline & Bottom (medium vs. large) & 130.10 & 41 & 127.76 & 40 & 0.73 & 0.40 & 0.1941 & 48 & 0.1733 & 47 & 5.65 & 0.02 \\
\hline \multirow[t]{3}{*}{ Density effect } & Off-bottom $(40 \%$ vs. $60 \%) * *$ & 97.60 & 47 & 92.01 & 46 & 2.79 & 0.10 & 0.0650 & 55 & 0.0648 & 54 & 0.14 & 0.71 \\
\hline & Suspended module ( $40 \%$ vs. $60 \%$ ) & 245.05 & 127 & 244.27 & 126 & 0.40 & 0.53 & 0.3111 & 207 & 0.3092 & 206 & 1.26 & 0.26 \\
\hline & Bottom ( $40 \%$ vs. $60 \%)$ & 255.70 & 83 & 253.79 & 82 & 0.62 & 0.43 & 0.3906 & 97 & 0.3906 & 96 & 0.00 & 0.95 \\
\hline \multirow{3}{*}{$\begin{array}{l}\text { Method effect } \\
\qquad(40 \% \text { density) }\end{array}$} & Off-bottom vs. suspended module & 237.36 & 105 & 215.36 & 104 & 10.62 & $<\mathbf{0 . 0 1}$ & 0.2432 & 152 & 0.2347 & 151 & 5.45 & 0.02 \\
\hline & Bottom vs. suspended module & 242.06 & 105 & 238.13 & 104 & 1.72 & 0.19 & 0.4139 & 152 & 0.3702 & 151 & 17.83 & $<\mathbf{0 . 0 0 0 1}$ \\
\hline & Off-bottom vs. bottom & 264.57 & 83 & 224.61 & 82 & 14.59 & $<\mathbf{0 . 0 0 1}$ & 0.3471 & 97 & 0.2575 & 96 & 33.43 & $<\mathbf{0 . 0 0 0 1}$ \\
\hline \multirow{3}{*}{$\begin{array}{l}\text { Method effect } \\
\text { (60\% density) }\end{array}$} & Off-bottom vs. suspended module $* *$ & 123.56 & 55 & 119.11 & 54 & 2.02 & 0.16 & 0.1203 & 79 & 0.1126 & 78 & 5.22 & 0.03 \\
\hline & Bottom vs. suspended module & 267.04 & 105 & 259.93 & 104 & 2.84 & 0.09 & 0.3572 & 152 & 0.3296 & 151 & 12.65 & $<\mathbf{0 . 0 0 1}$ \\
\hline & Off-bottom vs. bottom $* *$ & 132.96 & 47 & 117.77 & 46 & 5.93 & 0.02 & 0.2298 & 55 & 0.1525 & 54 & 27.36 & $<\mathbf{0 . 0 0 0 1}$ \\
\hline
\end{tabular}

Pooled residual sum of squares $\left(\mathrm{RSS}_{\mathrm{p}}\right)$, summed residual sum of squares $\left(\mathrm{RSS}_{\mathrm{s}}\right)$, degrees of freedom $(d f)$, and associated $F$-value $(F)$ and $P$-value $(P)$ are shown. Comparisons showing significant differences are shown in bold $(P<0.05)$.

$* *$ Indicates comparisons restricted to the medium cohort due to a lacking off-bottom large $60 \%$ group. 


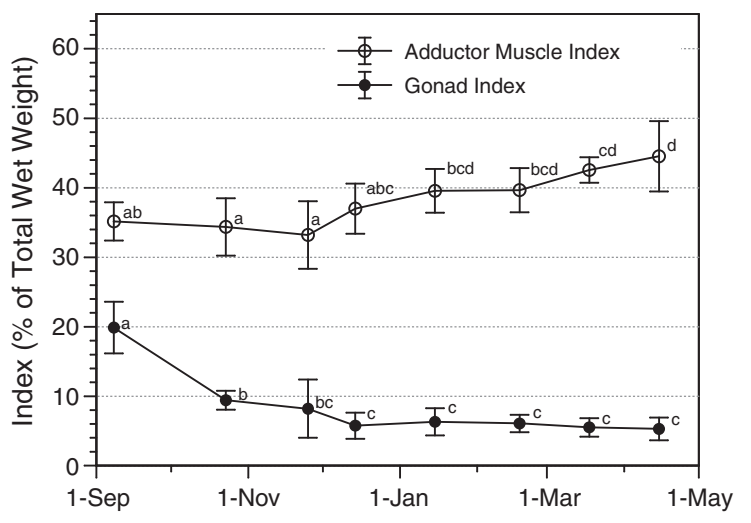

Fig. 5. N. subnodosus gonad and adductor muscle indices. Average values displayed with standard deviation $( \pm)$ represented by the bar. For each index, samplings not sharing the same subscript are significantly different by ANOVA followed by post-hoc Tukey test $(* P<0.05)$

varied little between 38 and $40 \mathrm{psu}$, typical of values throughout the year (Koch, pers. obs.).

\subsection{Returns model}

The differences in growth $(K)$ and mortality $(Z)$ values between grow-out methods greatly affected harvest weight and the resulting harvest value (Fig. 7). Off-bottom culture was the only method that is able to make any substantial gains with a full recuperation of costs. Returns reached a maximum value of US\$2201 (2.89 years, August 24th) at 40\% density and US\$343 (2.69 years, June 16th) at 60\% density. High material and operational costs hindered monetary gains in the suspended module $40 \%$ treatment, which required nearly two fulltime workers to maintain the culture at that density. Despite low costs, high mortality in the bottom culture treatments prevented any substantial gains in harvest value and resulting monetary returns.

For the two best performing treatments, off-bottom $40 \%$ and $60 \%$, the forecasted 10 -year culture period predicted about 5-6 years for both treatments to become profitable (Fig. 8). While the $40 \%$ treatment obtained a higher NPV $\left(\mathrm{NPV}_{10}=\mathrm{US} \$ 31,216, \mathrm{IRR}_{10}=21.6 \%\right)$, the $60 \%$ treatment was more profitable with a higher IRR $\left(\mathrm{NPV}_{10}=\mathrm{US} \$ 28,631, \mathrm{IRR}_{10}=27.0 \%\right)$. Simulation of different-sized culture operations revealed that larger operations do not substantially increase profitability (Fig. 9).

The sensitivity analysis showed that NPV is most sensitive to changes in sale price (price of adductor muscle), followed by the growth $(K)$ and mortality $(Z)$ parameters for grow-out (Fig. 10). Parameters relating to materials costs (grow-out density, materials costs and lifespan of materials) were more sensitive than labor costs (minimum wage). Parameters relating to seed grow-out were the least sensitive.

\section{Discussion}

\subsection{Factors influencing growth and mortality}

The higher mortality and decreased growth observed during the period of late summer to early fall was probably due to unfavorable abiotic conditions (high temperature and low oxygen concentrations), which can affect scallops' ability to respire and metabolize energy (Barber and Blake, 1985; Bricelj and Shumway, 1991). In September, the Gonad Index of N. subnodosus was highest and Adductor Muscle Index was depressed, indicating that the scallops had used much of the stored energy of the adductor muscle for gamete production, typical in scallops (Barber and Blake, 1981; Epp et al., 1988; Martínez, 1991; Pazos et al., 1997). Most scallops contain relatively low amounts of glycogen in the adductor muscle (Sundet and Vahl, 1981; Epp et al., 1988; Racotta et al., 2003), and so provide little relief to anaerobic requirements, especially during reproductive periods when carbohydrate stores are particularly low. However, immature Lion's Paw spat (3-30 mm) cultured at the same location grew better in fall under warm water conditions (Koch et al., 2005), indicating that non-reproductive juveniles may have a higher temperature tolerance than mature adults.

Alternatively, scallops responded positively to the colder conditions of late December and early January $\left(<20^{\circ} \mathrm{C}\right)$ in terms of shell growth and as a starting point for adductor muscle recovery. Favorable growth may be attributable to the post-spawning period, yet colder conditions may also be closer to the optimal temperature range for $N$. subnodosus. While the species has a wide distribution from the Baja California peninsula down to Péru (Keen, 1972), scallops are found in shallow waters only in the colder north, where $N$. subnodosus thrives in the greatest numbers (Laguna Ojo de Liebre). The colder conditions experienced during winter in Bahia Magdalena may more closely resemble the temperate regime of northern Baja California $\left(12-18{ }^{\circ} \mathrm{C}\right)$.

Racotta et al. (2003) concluded that Bahía Magdalena is an adequate site for Lion's Paw culture based on growth performance and energy allocation in different tissues preceding and following gametogenesis. While this may be true for culture conducted in the cooler, deep part of the bay, the situation in the mangrove channels such as estero San Buto is different due to the increased 

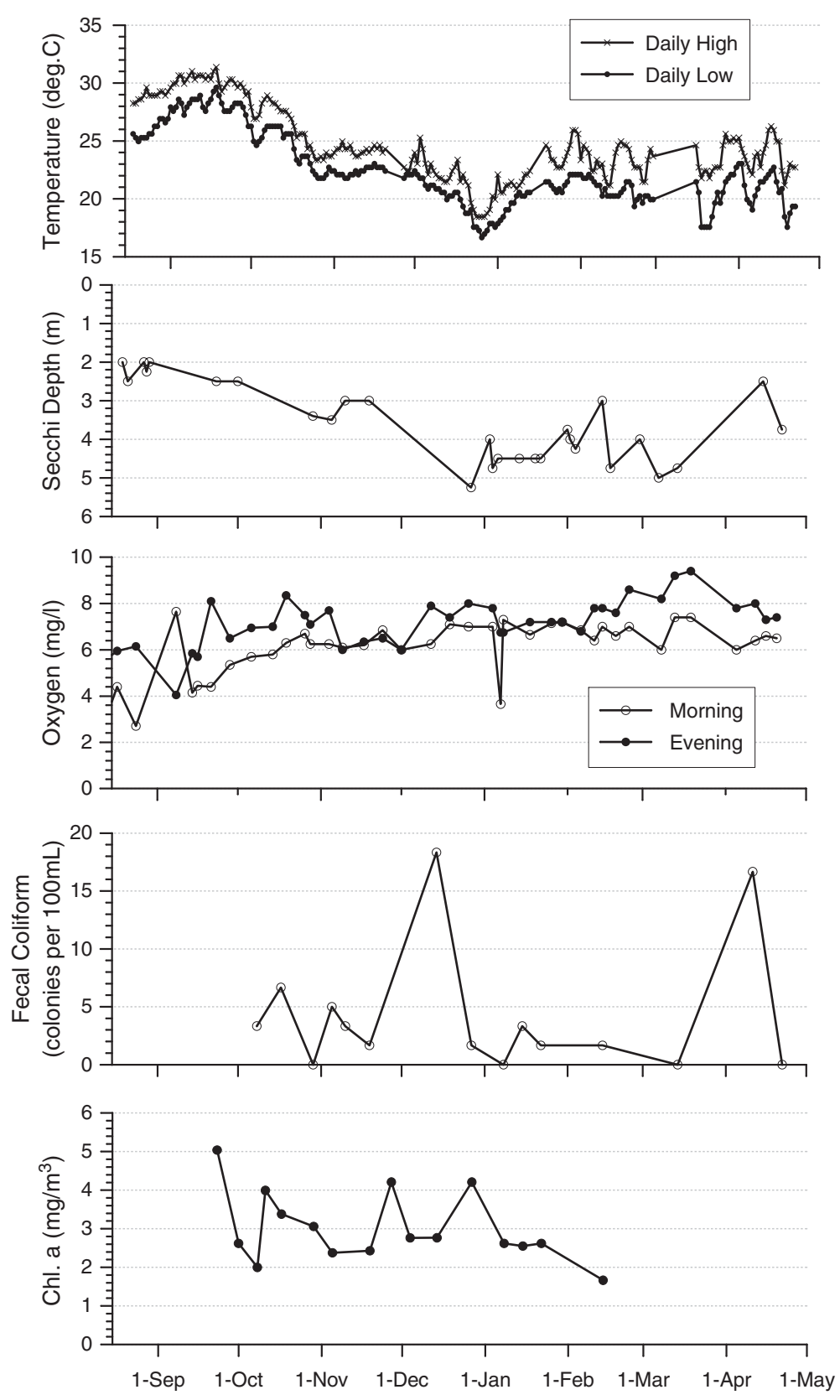

Fig. 6. Abiotic parameters, Secchi depth (m), temperature $\left({ }^{\circ} \mathrm{C}\right), \mathrm{O}_{2}\left(\mathrm{mg} \cdot l^{-1}\right), \mathrm{Chl} a\left(\mu \mathrm{g} \cdot l^{-1}\right)$ and fecal coliform (colonies $\left.100 \mathrm{ml} l^{-1}\right)$ recorded at estero San Buto during the study period.

metabolic stresses caused by the more extreme abiotic conditions. Lion's Paw spat grow well under the warm water conditions and so culture may begin in the early fall in order to take advantage of the strong winter growth period. Harvest of mature adults should however be conducted in late spring to early summer when adductor muscles are thickest, thus achieving higher yields and avoiding the increased mortality associated with the warm conditions.

\subsection{Effect of culture treatment}

Despite several previously successful pilot studies on the grow-out of N. subnodosus (Garcia-Dominguez et al., 1992; Morales-Hernández and Cáceres-Martínez, 1996; Felix-Pico, 1999; Barrios et al., 2003; Racotta et al., 2003), culture under shallow water conditions is relatively new. Suspended culture is often preferred due to faster grow-out times associated with the upper water 

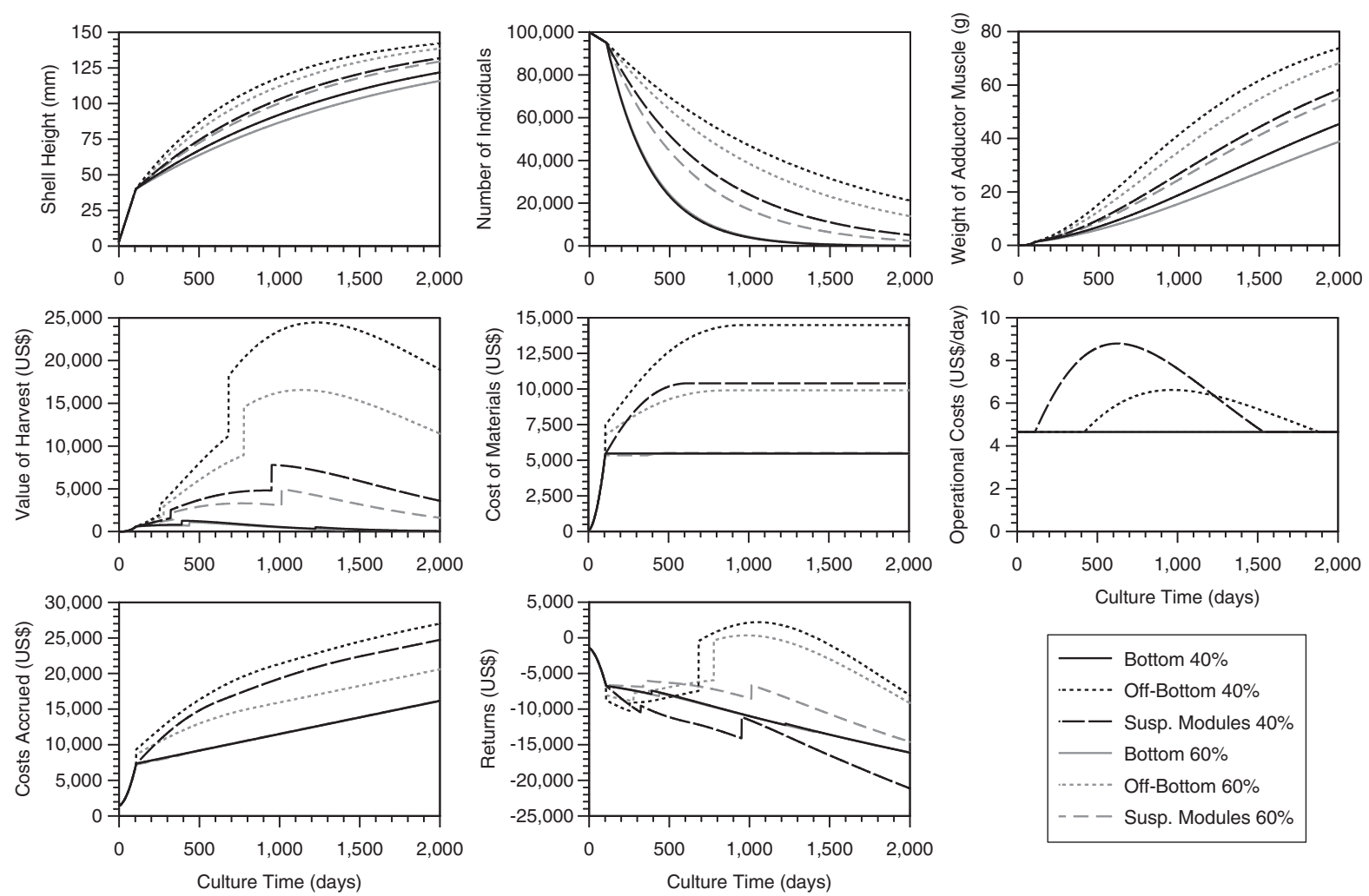

Fig. 7. Output of N. subnodosus. Returns model and associated parameters through time. All treatments ( 3 methods $\times 2$ densities) of the study are modeled separately.

column (Dadswell and Parsons, 1991). Shallow water bottom culture, which essentially takes advantage of the same upper water column characteristics, has been shown to provide comparable growth performance to more expensive and labor-intensive suspended culture for the sea scallop Placopecten magellanicus (Kleinman et al., 1996). This was also the case in estero San Buto, however, in our study shallow water off-bottom culture is actually superior to suspended culture in both growth and mortality, and thus other factors besides location within the water column probably attribute to its success.

Off-bottom culture functions well to improve growth and mortality over that of suspended modules, which is probably due to improved circulation as well as allowing excrement to fall more easily outside of the costales. Being slightly elevated off the sea floor may also contribute to improved performance over bottom culture through improved seston quality (Emerson et al., 1994). Fouling is a continual problem in suspended modules, which need to be cleaned thoroughly to maintain circulation. Even with fouling that occurs on the costales, the large mesh size serves well to maintain circulation and being that costales are also much easier to clean than the modules, cleaning efficiency is improved.
Bottom culture provides the poorest performance in growth and mortality of the treatments. This is in contrast to similar studies that have found bottom culture to actually improve growth though the creation of more natural conditions where scallops may be able to take advantage of food at the sediment/water interface (Vélez et al., 1995). We hypothesize that the densities tested were too high and that scallops were negatively affected by poor circulation. The foulsmelling odor in the bottom treatment, evident near the end of the culture period and likely due to excrement and pseudofeces accumulation, supports this. Mendoza et al. (2003) also observed poor performance in bottom culture of Nodipecten nodosus cultured at starting densities of $30 \%$ coverage. Lower densities, as were used by Vélez et al. (1995) for the grow-out of Euvola ziczac (final density $\sim 25 \%$ ), may allow for better performance. Scallops not used in this study and kept in low-density storage corrals $(<10 \%$ coverage) were also found to have grown much faster with low mortality (Sínsel and Taylor, pers. obs.) and should be further evaluated as this method will further reduce costs, creating substantially higher financial gains. 


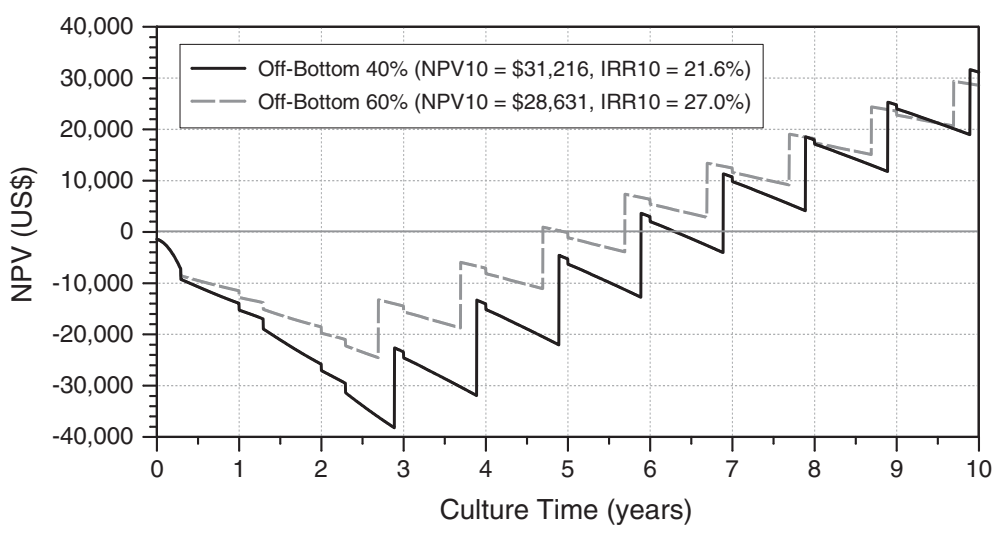

Fig. 8. 10-year simulation of net present value $\left(\mathrm{NPV}_{t}\right)$ for $40 \%$ and $60 \%$ density off-bottom culture at an initial culture size of 100,000 seed. Discount rate equals $6.6 \%$. Final values of $\mathrm{NPV}_{10}$ and $\mathrm{IRR}_{10}$ are provided in the key.

Given the associated metabolic stresses mentioned above, it is important to maintain good circulation and water-exchange in order to meet aerobic demands. Where circulation is high, such as with the off-bottom method, the scallops seem better able to cope with these stressful abiotic conditions.

\subsection{Economic evaluation}

Off-bottom culture was the method of choice in terms of monetary returns as well. Improved growth and, more importantly, a reduction in mortality provided a much higher harvestable weight than the other two methods. This increase in harvest weight allowed for a full recovery of the associated costs of culture after $\sim 2.75$ years, which is similar to other culture durations for large scallops (Dadswell and Parsons, 1992; Penney and Mills, 2000). Off-bottom culture at $60 \%$ density is predicted to be the most economically viable of the tested culture treatments even at a small scale of 100,000 seed. Growth and mortality were only slightly poorer than the $40 \%$ density (not statistically different), yet the reduced costs allow for a higher profitability over time. While the trend is positive, the rate of returns may not be attractive enough to entice investment from the average fisherman in the area given that the culture operation remains 'in the red' for the first 6 years.

Sale price is shown to be the most sensitive parameter for profits, which is similar to the findings of Penney and Mills (2000) for the culture of the sea scallop P. magellanicus. It is possible that culturists may be able to improve profitability by selling directly to consumers or through specialty markets as have been suggested by some authors (Penney and Mills, 2000; Mendoza et al., 2003). Such options may include the sale of large individuals in the shell $(10-12 \mathrm{~cm})$, which

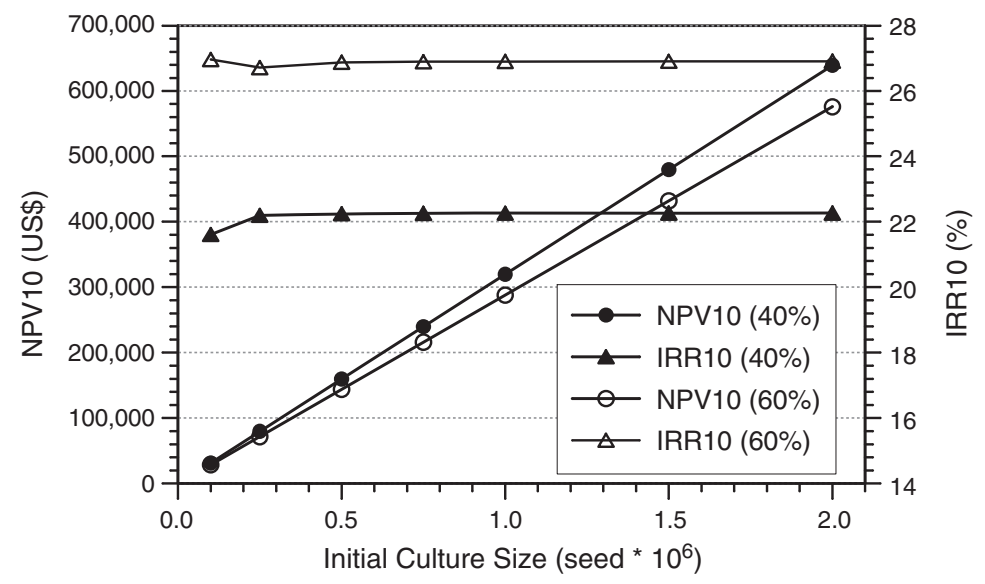

Fig. 9. Relationship between initial culture size (i.e. starting number of scallop seed), net present value $\left(\mathrm{NPV}_{10}\right)$ and internal rate of return (IRR 10$)$ for a 10 -year culture period of off-bottom culture at $40 \%$ and $60 \%$ densities. 


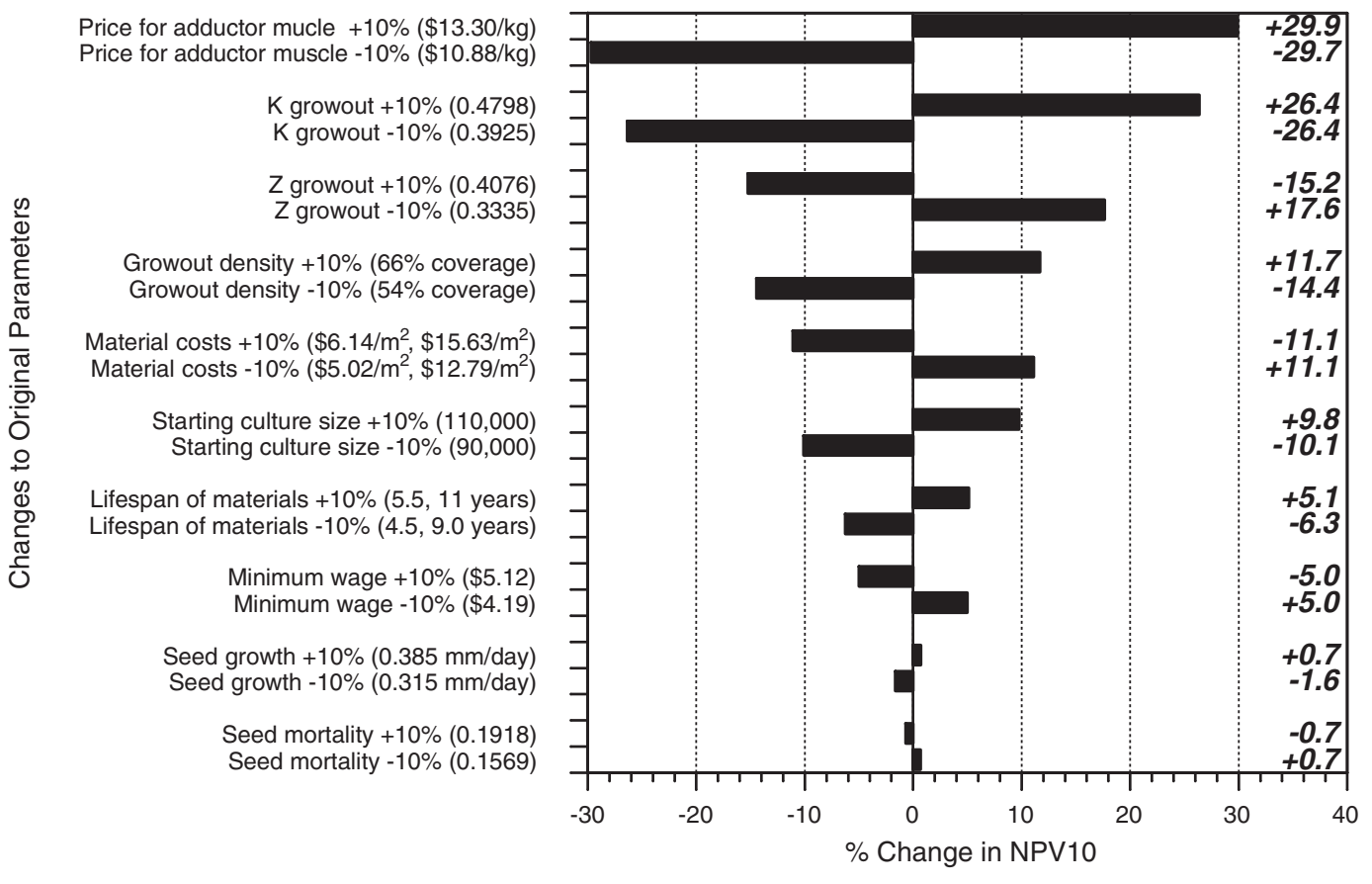

Fig. 10. Sensitivity analysis. Percent change in net present value $\left(\mathrm{NPV}_{10}\right)$ for a 10 -year simulation of $60 \%$ density off-bottom culture with adjustments of $\pm 10 \%$ to single parameters.

yields a higher price (US\$0.65) (Mazón-Suastegui, pers. comm.). Materials costs also have a substantial effect on profits and it seems likely that these costs can be reduced at the culture scale proposed for the model. An increase in labor costs over a minimum wage, as may be necessary to attract employees, is seen to be one of the least sensitive parameters and thus could be increased without affecting profits greatly.

Changes to parameters of growth and mortality are more sensitive for grow-out than for the seed stage, as grow-out constitutes $88 \%$ of the total culture time. The link between these parameters and prevailing abiotic conditions creates uncertainty in future economic projections due to environmental variability. Furthermore, the data suggests that growth performance is depressed during warmer temperatures and, considering that our study did not include some of the warmer summer months, the entered values may be overly optimistic.

Overall, profitability is fairly sensitive to changes in several parameters and thus results should be taken with caution. Finding ways to reduce overall costs and increase profitability (e.g. low-density bottom culture) will allow for a reduction in risk, thus increasing attractiveness for investment.

The model proposed in this study proves to be a valuable tool in determining the best method of culture given growth and mortality performance and the associated costs of culture. Additional costs will need to be added later such as for permits, scallop processing and transportation to market. The special VBGF worked well to simulate growth, giving reasonable estimates of shell height at age. The assumption for an infinite shell height of $150 \mathrm{~mm}$ for Bahía Magdalena is considered appropriate for the fitting of the VBGF given that no significant differences in the growth constant $K$ are seen between different sized cohorts of the same treatment.

The lack of a full year of grow-out data prevented modeling changes in growth and mortality through time, even though seasonality was seen to exist. Incorporation of the seasonal VBGF (Pitcher and MacDonald, 1973; Cloern and Nichols, 1978; Pauly and Gaschuetz, 1979) would yield a more accurate model with a better determination of harvest time. A full year of growth data is however recommended in order to correctly fit an oscillating seasonal VBGF. Ideally, a model that takes into account temporal changes in growth, mortality and somatic production (i.e. matrix-based model) would be the most accurate predictor of the optimal harvest date. In the end, our returns model provided valuable information to determine the profitability of a given culture method and is a useful tool to aquaculturists, especially in situations where pilot studies can be conducted. 
Shallow water scallop culture remains an attractive option for aquaculture development due to a less technically demanding culture operation, thus requiring a smaller investment in equipment. While additional research is needed, $N$. subnodosus seems a possible species for culture in the region. The culture techniques need to be optimized, however, to increase monetary returns and provide an incentive to local resource users.

\section{Acknowledgements}

The authors would like to thank José Manuel MazónSuástegui, Miguel Robles Mungaray and the Centro de Investigaciones Biológicas del Noroeste, S.C. (CIBNOR) for their technical support in providing the seed for cultivation and other resources. The authors gratefully acknowledge the financial and logistical support provided by the School for Field Studies, Center for Coastal Studies, Puerto San Carlos. We are grateful for all the help provided by Deborah Purce, Adina Ringler, Tania Schweers and the following students of the SFS Center for Coastal Studies who worked in the project: Lauren Kavanaugh, Megan Y. Lew, Steven Piro and Erin Riley. We also acknowledge the two anonymous reviewers whose recommendations greatly improved the earlier manuscript.

\section{References}

Barber, B.J., Blake, N.J., 1981. Energy storage and utilization in relation to gametogenesis in Argopecten irradians concentricus (Say). J. Exp. Mar. Biol. Ecol. 52, 121-134.

Barber, B.J., Blake, N.J., 1985. Substrate catabolism related to reproduction in the bay scallop Argopecten irradians concentricus, as determined by $\mathrm{O} / \mathrm{N}$ and RQ physiological indexes. Mar. Biol. (Heidelberg) 87, 13-18.

Barrios, D., Chávez, J., Cáceres, C., 2003. First trial of growth of Lyropecten subnodosus under culture conditions in Bahía La Paz, B.C.S., Mexico. Aquac. Res. 34, 633-639.

Brey, T., 2001. Population dynamics in benthic invertebrates. A virtual handbook. Version 01.2. http://www.awi-bremerhaven.de/Benthic/ Ecosystem/FoodWeb/Handbook/main.html. Alfred Wegener Institute for Polar and Marine Research, Germany.

Bricelj, V.M., Shumway, S., 1991. Physiology: energy acquisition and utilization. In: Shumway, B. (Ed.), Scallops: Biology, Ecology and Aquaculture. Elsevier Press, pp. 305-376.

Chávez, J., Cáceres, C., 1992. Scallop culture in the northwest of Mexico. World Aquac. 23, 20-26.

Chen, Y., Jackson, D.A., Harvey, H.H., 1992. A comparison of von Bertalanffy and polynomial functions in modelling fish growth data. Can. J. Fish Aquat. Sci. 49, 1228-1235.

Cloern, J.E., Nichols, F.H., 1978. A von Bertalanffy growth model with a seasonally varying coefficient. J. Fish. Res. Board Can. 35, 1479-1482.

Dadswell, M.J., Parsons, G.J., 1991. Potential for aquaculture of sea scallop, Placopecten magellanicus (Gmelin, 1791) in the Canadian maritimes using naturally produced spat. In: Shumway, S.E., Sandifer, P.A. (Eds.), An International Compendium of Scallop Biology and Culture. World Aquaculture Society, Baton Rouge, LA, pp. 300-307.

Dadswell, M.J., Parsons, J., 1992. Suspended Culture Growout Strategies Exploiting the Life-history Characteristics of Various Populations of Sea Scallops, Placopecten magellanicus.

Duggan, W.P., 1973. Growth and survival of the bay scallop, Argopecten irradians, at various locations in the water column and at various densities. Proc. Natl. Shellfish. Ass. 63, 68-71.

Emerson, C.W., Grant, J., Mallet, A., Carver, C., 1994. Growth and survival of sea scallops Placopecten magellanicus: effects of culture depth. Mar. Ecol. Prog. Ser. 108, 119-132.

Epp, J., Bricelj, V.M., Malouf, R.E., 1988. Seasonal partitioning and utilization of energy reserves in two age classes of the bay scallop Argopecten irradians irradians (Lamarck). J. Exp. Mar. Biol. Ecol. 121, 113-136.

Felix-Pico, E.F., 1991. Mexico. In: Shumway, B. (Ed.), Scallops: Biology, Ecology and Aquaculture. Elsevier Press, pp. 943-980.

Fylstra, D., Lasdon, L., Watson, J., Waren, A., 1998. Design and use of the Microsoft Excel Solver. Interfaces 28, 29-55.

Garcia-Dominguez, F., Castro-Moroyoqui, P., Felix-Pico, E., 1992. Spat settlement and early growth of Lyropecten subnodosus (Sowerby 1835) in Laguna Ojo de Liebre, B.C.S., Mexico, 19891990. J. Shellfish Res. 11, 195.

Keen, A.M., 1972. Sea Shells of Tropical West America. Stanford University Press, Stanford, California. 1064 pp.

Kleinman, S., Hatcher, B.G., Scheibling, R.E., Taylor, L.H., Hennigar, A.W., 1996. Shell and tissue growth of juvenile sea scallops (Placopecten magellanicus) in suspended and bottom culture in Lunenburg Bay, Nova Scotia. Aquaculture 142, 75-97.

Koch, V., Mázon Suastegui, J.M., Robles Mungaray, M., Dunn, D., 2005. Lion's Paw scallop (Nodipecten subnodosus, Sowerby 1835) aquaculture in Bahia Magdalena, Mexico: effects of population density and season on juvenile growth and mortality. Aquac. Res. 36, 505-512.

Lodeiros, C.J., Rengel, J.J., Freites, L., Morales, F., Himmelman, J.H., 1998. Growth and survival of the tropical scallop Lyropecten (Nodipecten) nodosus maintained in suspended culture at three depths. Aquaculture 165, 41-50.

Lodeiros, C.J., Rengel, J.J., Guderley, H.E., Nusetti, O., Himmelman, J.H., 2001. Biochemical composition and energy allocation in the tropical scallop Lyropecten (Nodipecten) nodosus during the months leading up to and following the development of gonads. Aquaculture 199, 63-72.

MacDonald, B.A., Thompson, R.J., 1986. Influence of temperature and food availability on the ecological energetics of the giant scallop Placopecten magellanicus: 3. Physiological ecology, the gametogenic cycle and scope for growth. Mar. Biol. (Heidelberg) 93, 37-48.

Martínez, G., 1991. Seasonal variation in biochemical composition of three size classes of the Chilean scallop Argopecten purpuratus Lamarck, 1819. Veliger 34, 335-343.

Mendoza, Y., Freites, L., Lodeiros, C.J., Lopez, J.A., Himmelman, J.H., 2003. Evaluation of biological and economical aspects of the culture of the scallop Lyropecten (Nodipecten) nodosus in suspended and bottom culture. Aquaculture 221, 207-219.

Morales-Hernández, R., Cáceres-Martínez, C., 1996. Pesquería de almeja mano de leon Lyropecten subnodosus. In: Casas-Valdez, M., Ponce-Diaz, G. (Eds.), Estudio del Potencial Pesquero de Baja California Sur, La Paz, pp. 87-100. 
Orensanz, J.M., Parma, A.M., Iribarne, O.O., 1991. Population dynamics and management of natural stocks. In: Shumway, B. (Ed.), Scallops: Biology, Ecology and Aquaculture. Elsevier Press, pp. 943-980.

Pauly, D., Gaschuetz, G., 1979. A Simple Method for Fitting Oscillating Length Growth Data, With a Program for Pocket Calculators. International Council for the Exploration of the Sea Charlottenlund, Denmarke. 26 pp.

Pazos, A.J., Roman, G., Acosta, C.P., Abad, M., Sanchez, J.L., 1997. Seasonal changes in condition and biochemical composition of the scallop Pecten maximus L. from suspended culture in the Ria de Arousa (Galicia, N.W. Spain) in relation to environmental conditions. J. Exp. Mar. Biol. Ecol. 211, 169-193.

Penney, R.W., Mills, T.J., 2000. Bioeconomic analysis of a sea scallop, Placopecten magellanicus, aquaculture production system in Newfoundland, Canada. J. Shellfish Res. 19, 113-124.

Pitcher, T.J., MacDonald, P.D.M., 1973. Two models for seasonal growth in fishes. J. Appl. Ecol. 10, 599-606.

Racotta, I.S., Ramirez, J.L., Ibarra, A.M., Rodriguez-Jaramillo, M.C., Carreno, D., Palacios, E., 2003. Growth and gametogenesis in the lion-paw scallop Nodipecten (Lyropecten) subnodosus. Aquaculture 217, 335-349.

Ratkowsky, D.A., 1983. Nonlinear Regression Modelling. Marcel Dekker Inc., New York, NY. 276 pp.

Reinecke, M.A., 1996. Madurez y desove de la almeja Mano de León Lyropecten subnodosus Sowerby, 1835 (Bivalvia: Pectinidae) en Laguna Ojo de Liebre, B.C.S. México. Bol. Pesq. CRIP-La Paz 3, $17-20$.

Ricker, W.E., 1975. Computation and interpretation of biological statistics of fish populations. Bulletin of the Fisheries Research Board of Canada, p. 191.
Sokal, R.R., Rohlf, F.J., 1995. Biometry: The Principles and Practice of Statistics in Biological Research. W. H. Freeman and Company, New York. 887 pp.

Solomon, E., Pringle, J.J., 1977. An Introduction to Financial Management. Goodyear Publishing Company, Santa Monica, California. 614 pp.

Strickland, J.D.H., Parsons, T.R., 1972. A Practical Handbook of Sea Water Analysis. Fisheries Research Board of Canada, Ottawa. $311 \mathrm{pp}$.

Sundet, J.H., Vahl, O., 1981. Seasonal changes in the dry weight and biochemical composition of the tissues of sexually mature and immature iceland scallops, Chlamys islandica. J. Mar. Biol. Assoc. U.K. 61, 1001-1010.

Unzueta-Bustamante, M.L., Olivas-Valdez, I.A., 1997. Evalauación del Potencial de Cultivo de Almeja Mano de Leon (Lyropeceten subnodosus) en el Município de Guaymas, Sonora, Mexico. Pub. CIBNOR. S.C. Unidad, p. 9.

Vakily, J.M., 1992. Determination and Comparison of Bivalve Growth, with Emphasis on Thailand and Other Tropical Areas. ICLARM, Manila (Philippines). 125 pp.

Vélez, A., Freites, L., Himmelman, J.H., Senior, W., Marin, N., 1995. Growth of the tropical scallop, Euvola (Pecten) ziczac, in bottom and suspended culture in the Golfo de Cariaco, Venezuela. Aquaculture 136, 257-276.

von Bertalanffy, L., 1938. A quantitative theory of organic growth (Inquiries on growth laws II). Hum. Biol. 10, 181-213. 